\title{
Clinical and functional outcomes of Rheumatoid Arthritis with analysis of disease characteristics.
}

\author{
Aya MG', Nihal A.F. ${ }^{2}$, Nagwa S.Ahmad ${ }^{3}$,Mohammed AI, \\ 1. Specialist of Rheumatology and Rehabilitation Faculty of Medicine .Assiut University \\ 2. Professor of Rheumatology and Rehabilitation Faculty of Medicine .Assiut University, \\ 3. Professor of Biochemistry, Faculty of Medicine, Sohag University, \\ 4. Assistant Professor of Rheumatology and Rehabilitation Faculty of Medicine Sohag,
}

\begin{abstract}
Objective: To investigate the relationship between quality of life (QOL), Anti-cyclic citrullinated peptide (Anti-CCP)and disease activity in patients with rheumatoid arthritis (RA).

Methods:200 patients with RA were included in the study. Data were obtained by questionnaires and laboratory investigation, which included several generic and disease related QOL instruments. Separate dimensions and physical and mental summary scores of the Short form Health survey (SF-36) and Health Assessment Questionnaire (HAQ) were compared to study the relationship between clinical and laboratory parameters with QOL, (Anti-CCP)and other disease related variables.

Results: Physical health related QOL was reported to be worse, and mental health related QOL better, in RA than in control. There was highly significant association between Disease Activity Score (DAS-28)and Anti-CCP value ( $\mathrm{p}<0.0001)$ comparing with control group. There were significance difference $(\mathrm{P}<0.05)$ about $(\mathrm{HAQ})$ andSF36 comparing with control.

Conclusions: RA has a significant effect on the health related qualityof life of patients. The disease duration was the most influencing factor on both the physical and mental function. Routine assessment of the HRQoL in those patients is recommended to detect and monitor the impact of the disease and its medications on different aspects.And a highly significant correlation was found between Anti-CCP value and disease activity in rheumatoid arthritis patients.
\end{abstract}

Keywords: Rheumatoid arthritis, Quality of life, Anti-CCP,DAS-28.

\section{Introduction}

Diseases such as RA are often characterized by the presence of autoantibodies. Rheumatoid factor is not specific for RA and may be present in patients with other diseases, such as hepatitis $\mathrm{C}$, and in healthy older persons. Anti-citrullinated protein antibody "Anti CCP" is more specific for RA and may play a role in disease pathogenesis ${ }^{(1 \& 2)}$. Approximately 50 to 80 percent of persons with RA have rheumatoid factor, anti-citrullinated protein anti-body, or both.Patients with RA may have a positive antinuclear antibody test result, and the test is of prognostic importance in juvenile forms of this disease, and both are components of new ACR 2010 criteria (3).

The RA activity and the degree of joint damage are critical in the evolution of the dysfunction. They had been measured by objective instruments, like the American College of Rheumatism (ACR) response criteria and the disease activity score for 28 joints (DAS-28) ${ }^{(4)}$. The ACR criteria measure the difference between two evaluation moments in a patient using joint assessment, patient and physician global assessment,the health assessment questionnaire (HAQ) ${ }^{(5)}$.

Rheumatoid arthritis (RA) is a chronic, multi-systemic autoimmune 
and inflammatory disease, which can result in significant functional disability and depressive symptoms. These changes may have a negative influence on the performance of daily living and work activities, with consequent impact on the quality of life (QOL) ${ }^{(6)}$.

Among the factors that could directly affect the reduction of QOL in patients with RA, depression deserves special attention. There was a close relationship between depression and the early stages of disability in patients with RA, and also that these patients became more depressed with the evolution of the disease ${ }^{(7)}$. Also the prevalence of depressive symptoms in patients with RA is of 33.7 and $53.2 \%$, respectively ${ }^{(\mathbf{8} \& 9)}$.

Moreover, the Disease-specific instrument included to measure functional limitations, the HAQ in RA was closely correlated to the physical functioning dimension of the 36-item short form (36-SF) health survey, therefore SF-36 is considered a valid instrument for measuring physical functioning and comparing different aspects of HRQoL in patients with $\mathrm{RA}^{(\mathbf{8})}$.

\section{Aim of the work:}

The aim of this work was to investigate the relationship between quality of life (QOL), Anti-cyclic citrullinated peptide (Anti-CCP) and disease activity in patients with rheumatoid arthritis (RA).

\section{Patients and Methods:}

This study was carried on 200 rheumatoid arthritis patients fulfilled the 2010 new classification criteria that represent a paradigm shift from the 1987 American College of Rheumatology criteria, which lagged sensitivity to detect early RA.

The patients recruited from the Rheumatoiology and Rehabilitation outpatient and inpatient clinics at Sohag and Assiut University Hospitals.
The Ethical committee of both University Hospitals approve the design of this study.

\section{Methods:}

It is a cross sectional study, evaluate the clinical outcomes of rheumatoid arthritis including the below measures. A checklist containing questions on demographic data (age, gender, formal education level, and work status) was completed by all subjects and was collected upon enrollment. All patients performed laboratory investigations and underwent a medical examination by a single rheumatologist who also determined the disease duration and assessed the disease activity score in 28-joints (DAS-28) . Patients were classified as in remission $(<2.6)$, low (P2.6 to <3.2), moderate (P3.2 to65.1), and high $(>5.1)$ disease activity. Extraarticular (EA)manifestations were identified clinically and confirmed using investigations when indicated. Current medication history was also collected. HRQoL was measured via the Medical Outcomes Study 36-SF health survey. SF-36 is a generic multidimensional measure of HRQoL that contains eight subscales representing physical functioning (PF), social functioning $(\mathrm{SF})$, role limitations due to physical health problems(RP), role limitations attributable to emotional problems(RE), mental health $(\mathrm{MH})$, vitality (VT), bodily pain (BP), and general health perceptions (GH). Higher scores of each subscale (which range from 0 to 100) indicate a better HRQoL. The physical and mental components of the eight scales are combined into physical (PCS) and mental (MCS) component summary scale scores.

\section{Statistical analysis:}

Date entry and data analysis were done using SPSS version 23(Statistical Package for Social Science). Data were presented as number, percentage, 
mean, standard deviation. Chi-square test and Fisher Exact test were used to compare between qualitative variables. Mann Whitney was used to compare quantitative variables between groups. P-value considered statistically significant when $\mathrm{P}<0.05$.

\section{Results}

This study included 200 patients with rheumatoid arthritis fulfilled 2010 ACR/EULAR classification criteria, and 50 healthy as controls.

Table (1) shows demographic data in study \& control groups. With nonsignificance difference in age, sex and marital status $(\mathrm{P}>0.05)$ comparing with control group.

Table (2) shows clinical data in study group. With $(70.0 \%)$ of patients had Swelling, also $(22.0 \%)$ had deformity, as regard there were $(38.0 \%)$ of patients had symptoms limited mobility, also there were $(48.0 \%)$ had constitutionals symptoms and there were $(44.0 \%)$ of patients in study group had extra. Art. Manifestations. Mean value of diseases duration 1.79 years, also there were mean value of MS=27.0 minutes. As regard there $(86.0 \%)$ of study group had pain. Fig (1) shows medications data in study group. With (46.0\%) using Methoteraxat (MTX), (52.0\%) using Leflunamide. As regard there were $(26.0 \%)$ using Sulphasalazine, also $(26.0 \%)$ of patients using systemic steroids and (62.0\%) using NSAIDS.

Table (3) shows laboratory data in study group with mean value of ESR $46.94 \mathrm{~mm} / \mathrm{h}$ with $(50.0 \%)$ of patients had high ESR1hr. , also there were $(71.0 \%)$ of patients positive RF and (32.0\%) of patients had high DAS28-ESR.

Table (4) shows comparison of rheumatoid factor "RF", "Anti-CCP" , HAQ and SF-36 according disease activity in study group. With significance difference $(\mathrm{P}<0.05)$ in Anti-CCP and $\mathrm{RF}$, and there were moderate significance difference $(\mathrm{P}<0.001)$ about HAQ \& SF-36.

Table (5) shows relation between clinical data and mean value HAQ in study group. There were moderate significance difference $(\mathrm{P}<0.001)$ between mean value of HAQ and pain, swelling, deformity, constitutionals symptoms and extra art. Manifestations. As regard there were highly significance difference $(\mathrm{P}<0.000)$ between mobility \& mean value of HAQ.

Table (1): Demographic data in study \& control groups.

\begin{tabular}{|c|c|c|c|}
\hline Item & $\begin{array}{l}\text { Study group } \\
\text { "n=200" }\end{array}$ & $\begin{array}{l}\text { Control group } \\
\text { "n=50" }\end{array}$ & P-value \\
\hline \multicolumn{4}{|l|}{ Age "years"a } \\
\hline $\begin{array}{l}\text { Mean } \pm \text { SD } \\
\text { (min-max) }\end{array}$ & $\begin{array}{l}43.68 \pm 9.35 \\
(19.0-65.0)\end{array}$ & $\begin{array}{l}40.02 \pm 7.22 \\
(20.0-66.0)\end{array}$ & $\mathrm{P}=0.709 \mathrm{n} . \mathrm{s}$ \\
\hline \multicolumn{4}{|l|}{$\operatorname{Sex}^{b}:$} \\
\hline Male & $20(10.0 \%)$ & $10(20.0 \%)$ & $\mathrm{P}=0.472 \mathrm{n} . \mathrm{s}$ \\
\hline Female & $180(90.0 \%)$ & $40(80.0 \%)$ & \\
\hline \multicolumn{4}{|l|}{ Marital status } \\
\hline Single & $24(12.0 \%)$ & $10(20.0 \%)$ & $\mathrm{P}=0.583 \mathrm{n} . \mathrm{s}$ \\
\hline Married & $176(88.0 \%)$ & $40(80.0 \%)$ & \\
\hline
\end{tabular}

${ }^{a}$ Using Mann-whiteny $\&^{b}$ Chi-square test 
Table (2): Clinical data in study group.

\begin{tabular}{ll}
\hline Item & Study group“n=200”no(\%) \\
\hline Arthralgia & $172(86.0 \%)$ \\
Swelling & $170(70.0 \%)$ \\
Deformity & $44(22.0 \%)$ \\
3-Constitutionals symptoms & $96(48.0 \%)$ \\
4-Extra. Art. manifestations & $1.79 \pm 0.96$ \\
5- D.M & $4(2.0 \%)$ \\
6- Disease duration “years" & $1.79 \pm 0.96$ \\
7-Morning Stiffness "minutes" & $27.0 \pm 5.87$ \\
\hline
\end{tabular}

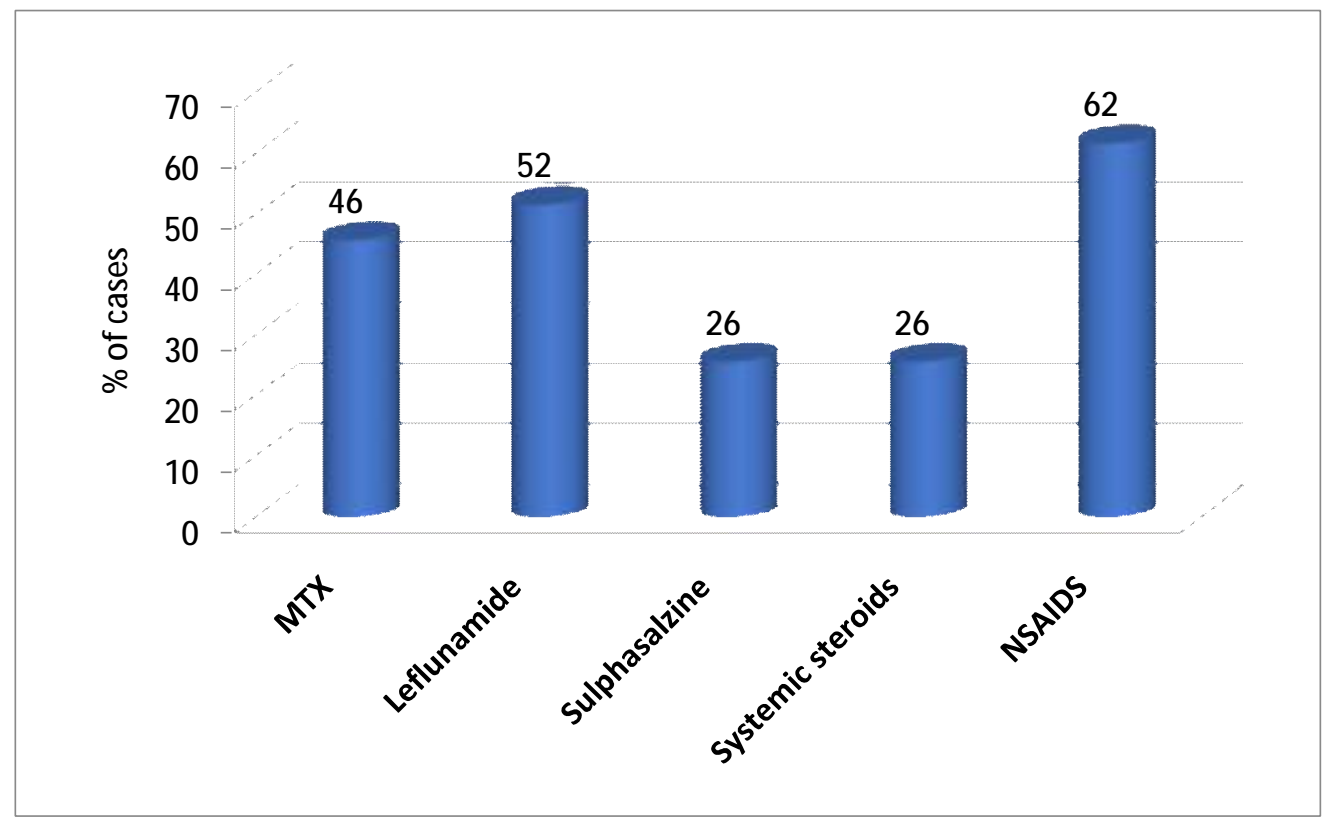

Fig (1): Medications data in study group.

Table (3): Laboratory data in study group.

\begin{tabular}{ll}
\hline Item & $\begin{array}{l}\text { Study group } \\
\text { "n=200" }\end{array}$ \\
\hline "ESR" $\mathbf{1}^{\text {st }} \mathbf{. h}$ 'mm/h" & $46.94 \pm 3.38$ \\
Hb "g/dl" & $11.50 \pm 0.28$ \\
Platelets "x10 $\mathbf{3 L} "$ & $321.09 \pm 10.08$ \\
4-WBCs "x10/uL" & $5.83 \pm 0.76$ \\
5-C- reactive protein "CRP" & $21.76 \pm 4.02$ \\
6-Rheumatoid factor "RF"'IU/ml" & $194.81 \pm 36.77$ \\
-ve & $58(29.0 \%)$ \\
+ve & $142(71.0 \%)$ \\
7- DAS28-ESR & $5.09 \pm 1.95$ \\
Low & $55(27.5 \%)$ \\
Moderate & $80(40.0 \%)$ \\
High & $65(32.5 \%)$ \\
\hline
\end{tabular}


Table (4): Comparison of rheumatoid factor "RF" , Anti - CCP , HAQ and SF36 data according disease activity in study group.

\begin{tabular}{lllll}
\hline Item & $\begin{array}{l}\text { Mild } \\
\text { "n=55" }\end{array}$ & $\begin{array}{l}\text { Moderate } \\
\text { "n=80" }\end{array}$ & $\begin{array}{l}\text { High } \\
\text { "n=65" }\end{array}$ & p-value \\
\hline $\begin{array}{l}\text { Anti-CCP"U/ml" } \\
\text { Positive">25" }\end{array}$ & $35(63.63 \%)$ & $58(72.5 \%)$ & $52(80.0 \%)$ & $\mathrm{P}<0.01^{*}$ \\
$\begin{array}{l}\text { Negative"<25" } \\
\text { RF "IU/ml": }\end{array}$ & $20(36.36 \%)$ & $22(27.5 \%)$ & $13(20.0 \%)$ & \\
Positive & & & & \\
Negative & $33(60.0 \%)$ & $56(70.0 \%)$ & $53(81.53 \%)$ & $\mathrm{P}<0.02^{*}$ \\
HAQ & $18(40.0 \%)$ & $24(30.0 \%)$ & $12(18.46 \%)$ & \\
SF-36 & $1.02 \pm 0.02$ & $1.75 \pm 0.05$ & $3.22 \pm 1.38$ & $\mathrm{P}<0.001^{* *}$ \\
& $86.67 \pm 4.56$ & $74.23 \pm 2.45$ & $45.62 \pm 2.57$ & $\mathrm{P}<0.001^{* *}$ \\
\hline
\end{tabular}

Table (5): Relation between Clinical data and HAQ in study group.

\begin{tabular}{lllll}
\hline Item & & $\begin{array}{l}\text { Study group } \\
\text { "n=200" }\end{array}$ & HAQ & p-value \\
\hline 1-Pain: & Yes & $172(86.0 \%)$ & $5.80 \pm 0.8$ & $\mathrm{P}<0.001^{* *}$ \\
& No & $28(14.0 \%)$ & $1.78 \pm 0.5$ & \\
2-Swelling: & Yes & $170(85.0 \%)$ & $5.43 \pm 0.6$ & $\mathrm{P}<0.002^{* *}$ \\
& No & $30(15.0 \%)$ & $1.53 \pm 0.3$ & \\
3-Deformity: & Yes & $44(22.0 \%)$ & $5.9 \pm 1.08$ & $\mathrm{P}<0.002^{* *}$ \\
& No & $156(78.0 \%)$ & $1.32 \pm 0.8$ & \\
4-Mobility: & Limited & $76(38.0 \%)$ & $5.99 \pm 0.82$ & $\mathrm{P}<0.000^{* * *}$ \\
& Not Limited & $124(62.0 \%)$ & $1.65 \pm 0.7$ & \\
5-Constitutionals & Yes & $96(48.0 \%)$ & $5.31 \pm 0.8$ & $\mathrm{P}<0.001^{* *}$ \\
symptoms: & No & $104(52.0 \%)$ & $1.47 \pm 0.2$ & \\
6-Extra. Articular & Yes & $88(44.0 \%)$ & $5.98 \pm 1.2$ & $\mathrm{P}<0.001^{* *}$ \\
manifestations: & No & $112(56.0 \%)$ & $1.02 \pm 0.7$ & \\
\hline
\end{tabular}

\section{Discussion}

Rheumatoid arthritis (RA) is a chronic inflammatory polyarthritis with a prevalence of $0.5 \%$ to $1 \%$ in the general population. ${ }^{-}$It has been accepted that initiating RA treatment at the early stage of disease improves clinical outcomes and prevents further joint destruction ${ }^{(\mathbf{1 0}) \text {. }}$

Because of the variable expressions of RA, different indices have been defined to evaluate the disease activity and response to treatment, for instance, Disease Activity Score in 28 Joints (DAS28) and Clinical Disease Activity Index (CDAI) $^{(11) .}$

This agree with (Castrejón, et al) ${ }^{(11)}$ who reportedDAS28-ESR and DAS28-CRP values are not interchangeable and that DAS28-ESR tends to produce higher values in women and long-term disease patients.

Castrejón et al. ${ }^{(11)}$ showed that DAS28-ESR tends to produce higher values in women and long-term disease patients.

In present study there were highly significance difference $(\mathrm{P}<0.000)$ in rheumatoid arthritis cases. This agree with Salaffi, et al., (12). Among several autoantibodies described in recent years in patients with RA, synthetic cyclic peptides containing citrulline $\mathrm{CCP}$ antibodies has been proposed as a new biomarker of disease severity .

Positivity of anti-CCP has been found in our and in several studies, to 
have prognostic properties in early (and very early) arthritis, although antiCCP antibodies may not be present at disease manifestation but may develop later in a percentage of RA patients (13).

Klareskog et al $^{(14)}$ reported that anti-CCP antibodies detected in preclinical phases of RA predict a poor radiographic outcome in early RA after 2 years of follow-up, Kroot et al, ${ }^{(15)}$ in a study of patients with early RA found that anti-CCP positive patients at follow up had developed significantly more radiographic damage than patients without this antibody. Similar to our results, Bukhari et al., ${ }^{(13)}$ found that the presence of anti-CCP antibodies at baseline was strongly associated with both prevalent erosions (odds ratio [OR] 2.53]) and developing erosions at 5 years (OR 10.2).

Hence, continuous remission is the desired target state. A variety of response scores for RA patients based on clinical and serological data have been proposed and applied in clinical trials. Among these, the American College of Rheumatology (ACR) response criteria, which rely on a relative change of five core set variables, and the European League Against Rheumatism (EULAR) response criteria, which are based on an absolute change of the composite Disease Activity Score in 28 joints (DAS28) including the ACR/EULAR remission criteria, are most common ${ }^{(\mathbf{1})}$.

The anti-CCP antibody test is a useful diagnostic and prognostic tool in RA Shamala, et al., (16) Studies have consistently pointed out the role of this antibody as a strong predictor of joint erosions in RA.

In present study there were highly significance difference between DAS28-ESR \& CRP this agree with Hansen et al., ${ }^{(17)}$ who reported earlier studies frequently showed that seropositive RA with high titers of autoantibodies and high CRP values at diagnosis are associated with more destructive disease with poorer outcome.

In the present study, seropositivity and anti CCP, R.F was significantly less common in the subjective group. This indicates that patients in the subjective group had good prognosis in average, and there would not be a great need for treatment intensification; however, DAS28 was higher than 3.2. Papadopoulos et al ${ }^{(18)}$.

In present study there were highly significance difference between pain, swelling, deformity and mobility with HAQ. This agree with Sharpeet al. observed that RA fatigue is a different phenomenon from normal tiredness because it is extreme, endless and unresolved described as an important and overwhelming complaint. Studies examining the predictive factors of fatigue in RA reported not only physical but also psychological and social aspects related to fatigue ${ }^{(7) .}$

Pain, physical disability, inactivity and poorer sleep quality and psychosocial factors, such as depressive symptoms, anxiety and social stress (as long-term symptoms or associated conditions) are predictive of fatigue in $\mathrm{RA}^{(\mathbf{1 2}) \text {. }}$

Yacoubet $a .^{(19)}$ assessed fatigue in 248 patients with RA, finding a prevalence of fatigue in approximately $90 \%$ and, in contrast to our results, a significant association with disease activity. Thyberget al. ${ }^{(20)}$ suggested that disease activity is among the factors closely related to fatigue.

Conceptually, a generic QOL instrument, the SF-36, waschosen to enable comparison between the patient samples. However, the SF-36 has only a few items relevant to upper extremity function, an important disabling aspect in RA. The disease-specific instruments included to measure functional limitations, the Health Assessment Questionnaire (HAQ) in 
RA was closely correlated to the physical functioning dimension of the SF-36 $(r=0.65)^{(21)}$.

Our findings are in agreement with other studies from India and elsewhere. Similar to another study from India, Patients with RA were found to have greater reduction in QOL than those without Ex. RA ${ }^{(22) .}$

However, on multiple regression analysis only HAQ independently affected QOL. After controlling for the effect of HAQ, disease activity did not have an independent effect on QOL. Thus, although disease activity affects QOL, the predominant effect is through its influence on the functional disability of the patient.

We therefore conclude that the SF-36 is a valid instrument for measuring physical functioning and comparing different aspects of health related QOL in patients with RA. Moreover the SF-36 captures a wider range of disability in RA, in which comorbidity may also have an important role.

\section{References}

1. Smolen JS, Landewé R, Bijlsma J, et al. EULAR recommendations for the management of rheumatoid arthritis with synthetic and biological disease-modifying antirheumatic drugs: 2016 update. Ann Rheum Dis. 2017;73(3):492509.

2. Smolen JS, Breedveld FC, Burmester GR, Bykerk V, Dougados M, Treating rheumatoid arthritis to target: 2014 update of the recommendations of an international task force. Ann Rheum Dis. 2015 May 12.

3. Huizinga TWJ, van der Helm-van Mil A. A quantitative approach to early rheumatoid arthritis. Bull NYU Hosp Joint Dis 2011; 69:11621.
4. Cader MZ, Filer A, Hazlehurst J, et al. Performance of the 2010 ACR/EULAR criteria for rheumatoid arthritis: comparison with 1987 ACR criteria in a very early synovitis cohort Ann Rheum Dis 2011; 70:949-55.

5. Weinblatt ME, Keystone EC, Furst DE, Kavanaugh AF, Chartash EK, Segurado OG. Long term efficacy and safety of adalimumab plus methotrexate in patients with rheumatoid arthritis: ARMADA 4 year extended study. Ann Rheum Dis 2006;65:753-9.

6. Anna Paula Ribeiro Campos; Cinthia Maria Silva; Shamyr Sulyvam de Castro; Cristiane Vitaliano Graminha, Depression and quality of life in rheumatoid arthritis individuals and stable health individuals: a comparative study. Fisioter. Pesqui. 2013;20(4).

7. Sharpe L, Sensky T, Allard S. The course of depression in recent onset rheumatoid arthritis: the predictive role of disability, illness perceptions, pain and coping. J Psychosom Res. 2001;51(6):713-9.

8. Costa AFC, Brasil MAA, Papi JA, Azevedo MNL. Depressão, ansiedade e atividade de doençan aartrite rheumatoid. Rev Bras Reumatol. 2008;48(1):7-11.

9. Mella LFB, Bertolo MB, Dalgalarrondo P. Depressive symptoms in rheumatoid arthritis patients. Rev Bras Psiquiatr. 2010;32(3):257-63.

10. Aletaha D, Neogi $T$, Silman AJ, et al. 2010 rheumatoid arthritis classification criteria: an American College of Rheumatology/ European League Against Rheumatism collaborative initiative. Ann Rheum Dis. 2010;69:1580-1588.

11. Castrejón1, A.M. Ortiz1, R. García-Vicuña1, J.P. Lopez-Bote1, A. Humbría1, L. Carmona2, I. Gonzalez-Alvaro1 sedimentation 
rate equivalent when estimating the 28-jointdisease activity score in rheumatoid arthritis? Clinical and Experimental Rheumatology 2008; 26: 769-775.

12. Salaffi F, Carotti M, Ciapetti A, Gasparini S, Filippucci E and Grassi W. Relationship between time-integrated disease activity estimated by DAS28-CRP and radiographic progression of anatomical damage in patients with early rheumatoid arthritis

13. Bukhari $\mathrm{M}$, Thomson $\mathrm{W}$, Naseem H, Bunn D, Silman A, Symmons D, Barton A: The performance of anti-cyclic citrullinated peptide antibodies in predicting the severity of radiologic damage in inflammatory polyarthritis: results from the Norfolk Arthritis Register. Arthritis Rheum. 2007, 56 (9): 2929-35.

14. Klareskog L, Catrina AI, Paget S: Rheumatoid arthritis. Lancet. 2009, 21:373 (9664): 659-72.

15. Kroot EJ, de Jong BA, van Leeuwen MA et al. The prognostic value of anti-cyclic citrullinated peptide antibody in patients with recent-onset rheumatoid arthritis. Arthritis Rheum.2000, 43: 1831-5.

16. Rajalingam S, Sakthiswary R, Hussein H. Anti-Citrullinated Cyclic Peptide Antibody and Functional Disability Are Associated With Poor Sleep Quality in Rheumatoid Arthritis Arch Rheumatol 2017;32(1):15-20.
17. Hansen IM, Andreasen R, Bui Hansen et al. The Reliability of Disease Activity Score in 28 JointsC-Reactive Protein Might Be Overestimated in a Subgroup of Rheumatoid Arthritis Patients, When the Score Is Solely Based on Subjective Parameters J Clin Rheumatol. 2017;23(2):102-6.

18. Papadopoulos IA, Katsimbri P, Katsaraki A, et al. Clinical course and outcome of early rheumatoid arthritis. Rheumatol Int. 2011;20:205-210.

19. IbnYacoub $Y$, Amine $B$, Laatiris A, Hajjaj-Hassouni N. Rheumatoid factor and antibodies against citrullinated peptides in Moroccan patients with rheumatoid arthritis: association with disease parameters and quality of life. Clin, Rheumatol 2012;31:329-34.

20. Thyberg I, Dahlström Ö, Thyberg M. Factors related to fatigue in women and men with early rheumatoid arthritis: the Swedish TIRA study. J Rehabil Med. 2009;4:905-12.

21. Chorus AMJ, Miedema HS, Wevers CWJ, van der Linden SM. Labour force participation among rheumatoid arthritis patients. Ann Rheum Dis .2000;59:549-54.

22. Haroon N, Aggarwal A, Lawrence $A$ et al. Impact of rheumatoid arthritis on quality of life. Mod Rheumatol. 2007;17:2905. 
